\title{
REVIEW
}

\section{Liquid Crystal-Based Emulsions: Progress and Prospects}

\author{
Mohammad Mydul Alam ${ }^{1}$ and Kenji Aramaki ${ }^{2 *}$ \\ ${ }^{1}$ Department of Chemistry, Faculty of Science and Engineering, Saga University, 1 Honjo-machi, Saga 840-8502, Japan \\ ${ }^{2}$ Graduate School of Environment and Information Sciences, Yokohama National University, Tokiwadai 79-7, Hodogaya-ku, Yokohama 240-8501, \\ Japan
}

\begin{abstract}
Recent progress in lyotropic liquid crystal (LC)-based emulsions over the last few years has been reviewed. The tuning parameters for the formation, stability, rheology and transparency of LC-based emulsions are addressed. Recent applications of LC-based emulsions to the fabrication of dual meso/ macroporous materials are also included.
\end{abstract}

Key words: self assembly, gel emulsions, liquid crystals, rheology, transparent emulsions, mesoporous materials

\section{INTRODUCTION}

Emulsions are dispersions of one liquid (dispersed phase) into another liquid (continuous phase); both liquids are immiscible in each other. Emulsions are thermodynamically unstable systems, and complete phase separation occurs if sufficient time is allowed. Emulsions are nonequilibrium systems, so their physical properties depend on the droplets size, concentration of the dispersed and continuous phase and the way of preparation. Due to the scientific and industrial importance of emulsions, researchers are making efforts to increase the stability of emulsions or to reduce emulsion-breaking processes, such as coalescence, flocculation and sedimentation. It is also important to not only increase the stability of the emulsion but also retain its physical and chemical properties. Rodriguez and Lazzari have published a complete review ${ }^{1)}$, in which they have shown that the physical properties and structures of emulsions can be tuned by using different types of continuous phase, such as lyotropic liquid crystals $^{2-4)}$, thermotropic liquid crystals ${ }^{5,6)}$, gelled continuous phases ${ }^{7-9)}$, crystalline continuous phases ${ }^{10,11)}$ and particles ${ }^{12-14)}$. Among the various continuous phase types, lyotropic liquid crystals are gaining much research interest because they provide opportunities for fabricating novel types of meso/ macoporous materials ${ }^{15,16)}$.

Liquid crystals (LCs) with different architectures can be formed by the self assembly of surfactants ${ }^{17-19)}$ or lipids ${ }^{20,21)}$ in aqueous ${ }^{22-24)}$ or nonaqueous ${ }^{2,25,26)}$ media, depending on the concentration, temperature and degree of unsaturation of the hydrocarbon chain. The most commonly reported liquid crystals are lamellar (crystalline, $\mathrm{L}_{\mathrm{c}}$ and amorphous $\left.\mathrm{L}_{\alpha}\right)$, hexagonal $\left(\mathrm{H}_{1}\right.$ and $\left.\mathrm{H}_{2}\right)$, discontinuous cubic $\left(\mathrm{I}_{1}\right.$ and $\left.\mathrm{I}_{2}\right)$ and bicontinuous cubic $\left(\mathrm{V}_{1} \text { and } \mathrm{V}_{2}\right)^{27)}$ phases. These liquid crystals possess fascinating viscoelastic properties, which make them useful in such industrial applications as dispersion technology, cosmetics, foods, fertilizers, minerals and encapsulation systems ${ }^{28-31)}$. The high viscosity of liquid crystals allows the preparation of LC-based emulsions in which the LC acts as the continuous phase ${ }^{32-34)}$. Also the stability of the LC-based emulsions is high since the emulsion droplets are trapped in the viscous LC matrix. At the same time, the LC-based emulsions show high viscosity even at low volume fraction of the dispersed phase ${ }^{3,35-38)}$, which could be a good property in wide application areas. However, it should be kept in mind that the liquid crystal structure could be modulated in presence of oil ${ }^{39)}$.

The term "gel emulsion" is sometimes confusing to readers when it refers to LC-based and conventional highly concentrated emulsions or high internal phase ratio emulsions (HIPREs). Here, we present anomalous behaviors between LC-based emulsions and HIPREs ${ }^{40-44)}$ to improve understanding of differences between these two systems. Although both emulsions are called "highly concentrated emulsions" or "gel emulsions," there are some distinct features observed in each of the two: (1) LC-based emulsions are formed in the region of the ternary phase diagram in

\footnotetext{
*Correspondence to: Kenji Aramaki, Graduate School of Environment and Information Sciences, Yokohama National University, Tokiwadai 79-7, Hodogaya-ku, Yokohama 240-8501, Japan

E-mail: aramakik@ynu.ac.jp

Accepted September 26, 2013 (recieved for review July 1, 2013)

Journal of Oleo Science ISSN 1345-8957 print / ISSN 1347-3352 online

http://www.jstage.jst.go.jp/browse/jos/ http://mc.manusriptcentral.com/jjocs
} 
which the excess oil or water phase coexists with the LC (acting as a continuous phase) ${ }^{3,4,37)}$, while HIPREs form where excess oil or water coexists with the micellar solu$\operatorname{tion}^{40,41)}$; (2) LC surrounds the droplets in LC-based emulsions, while a micellar phase surrounds the dispersed phase in conventional HIPREs; (3) LC-based emulsions show high viscosity even at low volume fractions of the dispersed phase $(<50 \%)^{36}$, while HIPREs show high viscosity only when the dispersed phase exceeds $74 \%$ volume fraction $^{45)}$; (4) LC-based gel emulsions often look translucent or transparent, depending on the composition and temperature, but HIPREs are mostly translucent or milky; and (5) the rheology of LC-based emulsions is mainly controlled by the LC (continuous phase $)^{46-50)}$, while HIPREs rheology is controlled by the volume fraction of the dispersed phase ${ }^{45}$.

In this review we summarized recent progress of formulation method, systems, transparency control and rheological properties of the LC-based emulsions. Also we mentioned a novel application of the LC-based emulsions as a template to synthesize mesoporous silica.

\section{FORMATION AND STABILITY OF LC-BASED EMULSIONS}

Structure of the LC-based emulsions is possible to be water- and oil-continuous ones, which is similar to conventional $\mathrm{O} / \mathrm{W}$ and $\mathrm{W} / \mathrm{O}$ emulsions. In many case, the continuous phase of the water-continuous type is a discontinuous cubic $\left(\mathrm{I}_{1}\right)^{3)}$ or a hexagonal phase $\left(\mathrm{H}_{1}\right)^{38)}$ whereas that of the oil-continuous type is a reverse discontinuous $\left(\mathrm{I}_{2}\right)^{37)}$ or a reverse hexagonal phase $\left(\mathrm{H}_{2}\right)^{50)}$ since we can often observe two-phase equilibrium with those liquid crystals in many water/surfactant/oil systems. In this section, we summarized preparation method and systems reported for the LCbased emulsions.

A preparation scheme of LC-based emulsions is presented in Scheme 1.
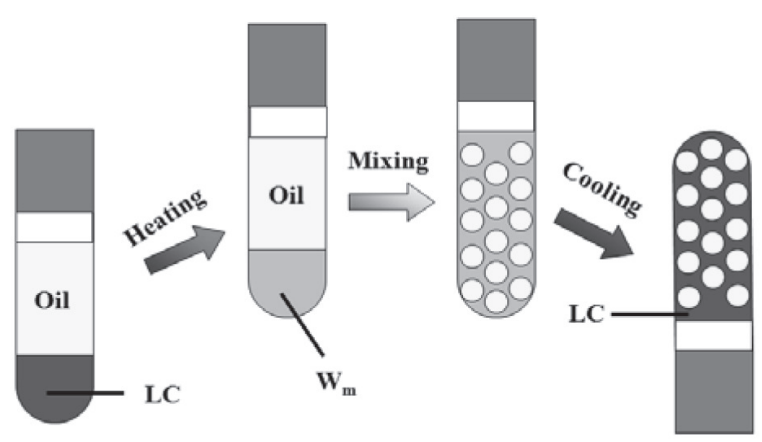

LC based emulsion

Scheme 1 Preparation of LC-based emulsion. Here LC means liquid crystals; $\mathrm{W}_{\mathrm{m}}$ indicates micellar phase.
It should be kept in mind that liquid crystals should be prepared at first with a proper composition of water, surfactant in presence or absence of oil. Then the excess oil is added to the liquid crystals as shown in Scheme 1 to make the final composition of the emulsion. As illustrated in Scheme 1, the melting of the LC is necessary for adequate mixing of the oil during preparation of the emulsion by this method. However, the thermal treatment may not be necessary by employing any suitable mechanical emulsification methods such as high pressure homogenizer, which is expected as a future study. Emulsion droplet size and size distribution are important factors for emulsion properties and applications and they are related to preparation methods. Few study regarding the droplet size and distribution for the LC-based emulsions have been done at this moment and further studies regarding those points will be expected in future.

Alam and Aramaki ${ }^{38,51)}$ have described that the formation and stability of cubic- $\left(\mathrm{O} / \mathrm{I}_{1}\right)$ and hexagonal- $\left(\mathrm{O} / \mathrm{H}_{1}\right)$ based emulsions depends on the nature of the surfactant and oil; use of high molecular weight hydrocarbon and triglyceride oils results in superior emulsion formation and stability. In Table 1, observations of the formation of $\mathrm{O} / \mathrm{H}_{1}$ emulsions are presented. The formation and stability of $\mathrm{O} / \mathrm{H}_{1}$ emulsions is highly oil-dependent; use of high molecular weight oil results in better formation and stability than use of low molecular weight oil.

Alam and Aramaki ${ }^{38)}$ also reported that the phase behavior of a nonionic surfactant (octaethyleneglycol dodecyl ether, $\mathrm{C}_{12} \mathrm{EO}_{8}$ ) aggregates during heating, mixing and cooling is vital to the formation and stability of the LCbased emulsions. A bicontinuous cubic phase $\left(\mathrm{V}_{1}\right)$ is observed when low molecular weight hydrocarbon oil (octane) is used to prepare LC-based emulsions (Fig. 1a); as a result, the formation of the emulsions was hampered. According to Scheme 1, the formation of LC-based emulsions is facilitated by the melting of the $\mathrm{LC}+\mathrm{O}$ phase to the $\mathrm{W}_{\mathrm{m}}+\mathrm{O}$ phase and subsequent return to the $\mathrm{LC}+\mathrm{O}$ phase without an intermediate phase during cooling. The phase behavior of liquid paraffin(Fig. 1b) follows the route of Scheme 1, resulting in better formation and more stable LC-based emulsions (Table 1).

The high melting temperature of the $\mathrm{LC}+\mathrm{O}$ phase also hampers the formation of LC-based emulsions, which was observed in the case of hexadecane oil, as shown in Fig. 1c. Recently, Alam et al..$^{52}$ also described the important role of surfactant hydrophilicity in the formation and rheology of LC-based emulsions; long-chain surfactants are especially more suitable for the formation of LC-based emulsions than short-chain surfactants. The formation of LC-based emulsions is not spontaneous, and several parameters must be considered during their preparation. Not only phase behavior but also oil solubility in the continuous phase could manipulate the formation of LC-based emulsions ${ }^{48)}$. 


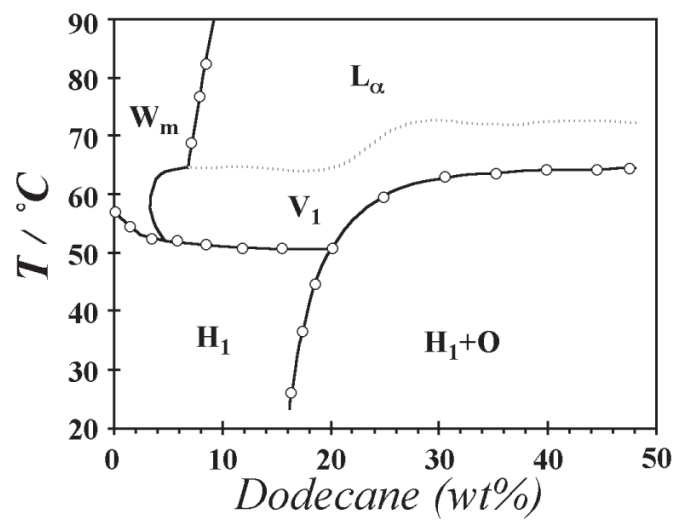

(a)

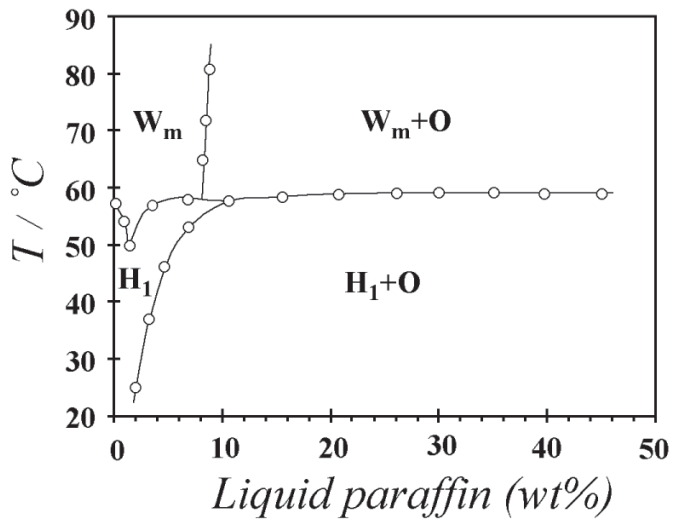

(b)

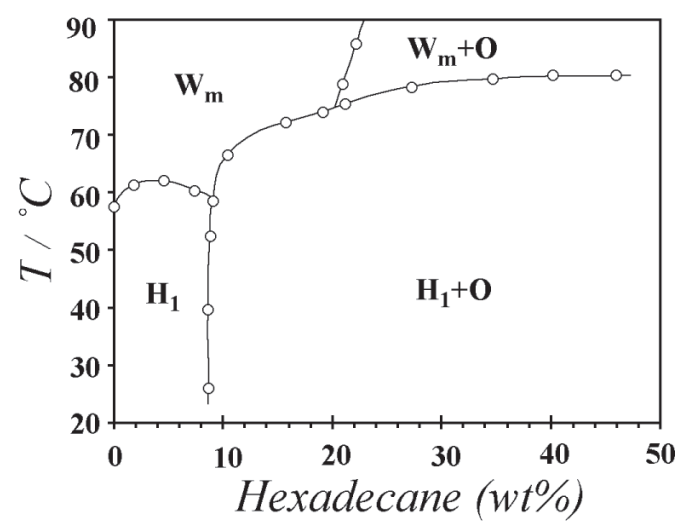

(c)

Fig. 1 Effect of temperature on the phase behavior of the $\mathrm{H}_{1}$ and $\mathrm{H}_{1}+\mathrm{O}$ phases at a fixed water/ $\mathrm{C}_{12} \mathrm{EO}_{8}(40 / 60)$ ratio, with different oil concentrations: (a) dodecane, (b) liquid paraffin and (c) hexadecane. Here, $\mathrm{W}_{\mathrm{m}}$ indicates micellar phase; $\mathrm{V}_{1}$, bicontinuous phase; $\mathrm{L}_{\alpha}$, lamellar phase; $\mathrm{O}_{\mathrm{m}}$, reverse micelle; $\mathrm{H}_{1}$, hexagonal phase; and $\mathrm{H}_{1}+\mathrm{O}$, hexagonal phase with excess oil phase. Adapted from reference ${ }^{38)}$.

Table 1 Results of visual observation of the samples prepared after 2 min for formation of $\mathrm{O} / \mathrm{H}_{1}$ gel emulsions using oils of different molecular weights, adapted from reference ${ }^{38)}$.

\begin{tabular}{lccccccccc}
\hline Oil content (wt\%) & 30 & 35 & 40 & 45 & 50 & 60 & 70 & 80 & 90 \\
\hline Heptane & $\bigcirc$ & $\bigcirc$ & $\bigcirc$ & $\bigcirc$ & $\times$ & $\times$ & $\times$ & $\times$ & $\times$ \\
Octane & $\bigcirc$ & $\bigcirc$ & $\bigcirc$ & $\bigcirc$ & $\bigcirc$ & $\times$ & $\times$ & $\times$ & $\times$ \\
Decane & $\bigcirc$ & $\bigcirc$ & $\bigcirc$ & $\bigcirc$ & $\times$ & $\times$ & $\times$ & $\times$ & $\times$ \\
Dodecane & $\bigcirc$ & $\bigcirc$ & $\bigcirc$ & $\bigcirc$ & $\times$ & $\times$ & $\times$ & $\times$ & $\times$ \\
Tetradecane & $\bigcirc$ & $\bigcirc$ & $\times$ & $\times$ & $\times$ & $\times$ & $\times$ & $\times$ & $\times$ \\
Hexadecane & $\bigcirc$ & $\times$ & $\times$ & $\times$ & $\times$ & $\times$ & $\times$ & $\times$ & $\times$ \\
Squalane & $\bigcirc$ & $\bigcirc$ & $\bigcirc$ & $\bigcirc$ & $\bigcirc$ & $\bigcirc$ & $\bigcirc$ & $\times$ & $\times$ \\
Liquid paraffin & $\bigcirc$ & $\bigcirc$ & $\bigcirc$ & $\bigcirc$ & $\bigcirc$ & $\bigcirc$ & $\bigcirc$ & $\bigcirc$ & $\times$ \\
\hline
\end{tabular}

Gel emulsion, $\times$ oil-separated 


\section{M. Alam and K. Aramaki}

\subsection{Normal liquid crystal-based emulsions}

In this section, we provide an overview of normal LCbased emulsions, as reported in the literature. Interest in liquid crystal-based emulsions began when Friberg reported in 1969 the role of LCs in preparation of emulsions ${ }^{32}$. After that report, a number of other articles addressed the same phenomena for the promising application of these emulsions in the cosmetic industry ${ }^{33,49,53-56)}$. In 2000, Rodriguez et $a l .{ }^{3)}$ were the first to report cubic phase-based gel emulsions $\left(\mathrm{O} / \mathrm{I}_{1}\right)$. They observed that $\mathrm{O} / \mathrm{I}_{1}$ emulsions could contain up to $90 \mathrm{wt} \%$ oil as a dispersed phase in which the $\mathrm{I}_{1}$ phase acts as the continuous phase. Rodriguez also mentioned that translucent $\mathrm{O} / \mathrm{I}_{1}$ emulsions could be transparent by tuning the refractive index between the dispersed and continuous phases. From microscopic observations, the droplet shape of $\mathrm{O} / \mathrm{I}_{1}$ emulsions was found to have a similar structure to that of conventional highly concentrated emulsions $^{42)}$; polydisperse and polyhedral droplets are surrounded by a thin film of continuous phase, as shown in Fig. 2. Rodriguez et $a l^{3)}$ noted that this type of emulsion shows prolonged stability due to the presence of highly viscous LCs, which reduces the likelihood of emulsion-breaking processes.

Due to the high viscosity of the LC, coalescence and creaming are reduced, enhancing the stability of the emulsions. A rheological study of $\mathrm{O} / \mathrm{I}_{1}$ emulsions was also conducted by Rodriguez et al. ${ }^{36)}$, who observed that the viscosity of $\mathrm{O} / \mathrm{I}_{1}$ emulsions decreases with increasing dispersed phase volume fraction, which is the opposite trend of conventional highly concentrated emulsions ${ }^{57)}$. Rodriguez et $a l$. explained that the decrease in the viscosity is simply due to the lower volume fraction of the continuous phase. Recently, cubic phase-based emulsions have been broadly

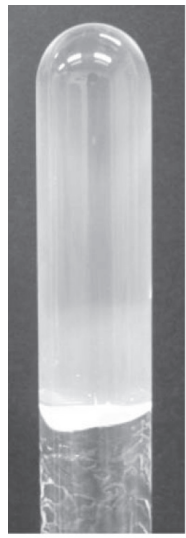

(a)

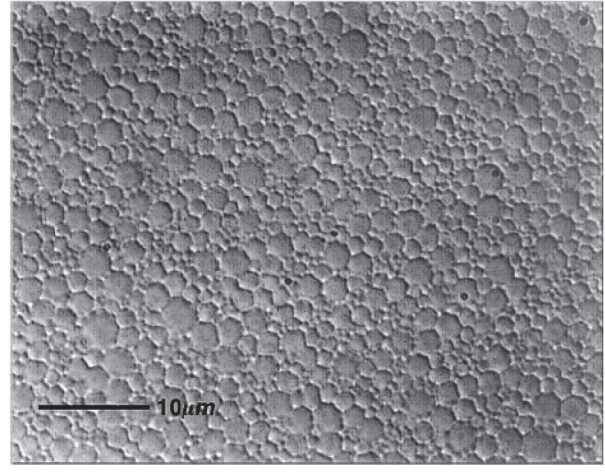

(b)
Fig. 2 (a) Photograph and (b) microscopic image of $\mathrm{O} / \mathrm{I}_{1}$ emulsions. Adapted from ref. 3.

studied by several groups ${ }^{34,35,47,58-61)}$. Kunieda et al. ${ }^{35)}$ noted that another type of LC-based emulsions, $\mathrm{O} / \mathrm{H}_{1}$, could be possible; however, further study was not conducted. In 2008, Alam and Aramaki ${ }^{38)}$ extensively studied hexagonal phase-based gel emulsions $\left(\mathrm{O} / \mathrm{H}_{1}\right)$ in a non-ionic surfactant, $\mathrm{C}_{12} \mathrm{EO}_{8}$, in which excess oil is in equilibrium with the $\mathrm{H}_{1}$ phase, as shown in Fig. 3a. The authors reported that formation and stability of $\mathrm{O} / \mathrm{H}_{1}$ emulsions are highly dependent on the nature of the oil; the use of high molecular weight oil results in better formation and higher stability than does use of low molecular weight oil ${ }^{38)}$.

Recently, Sharma and Warr ${ }^{24)}$ have reported the structure of $\mathrm{O} / \mathrm{H}_{1}$ emulsions by using an optical microscope. They observed that the droplet shape of $\mathrm{O} / \mathrm{H}_{1}$ emulsions changes from spherical to polyhedral depending on the oil

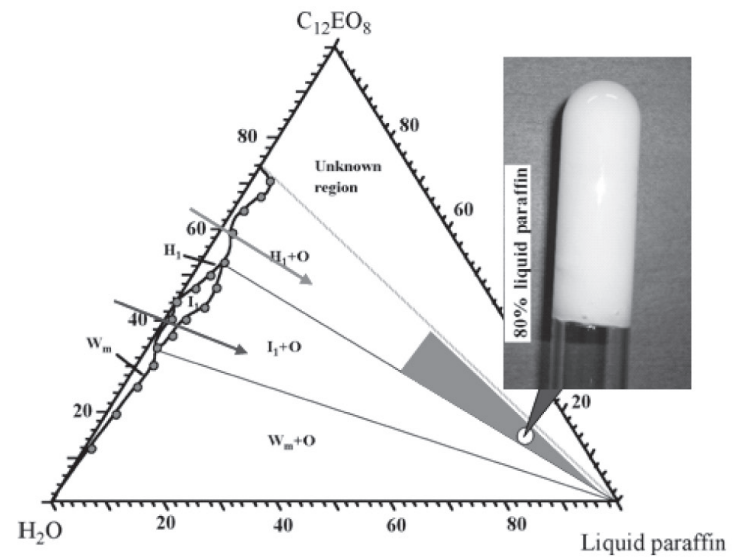

(a)

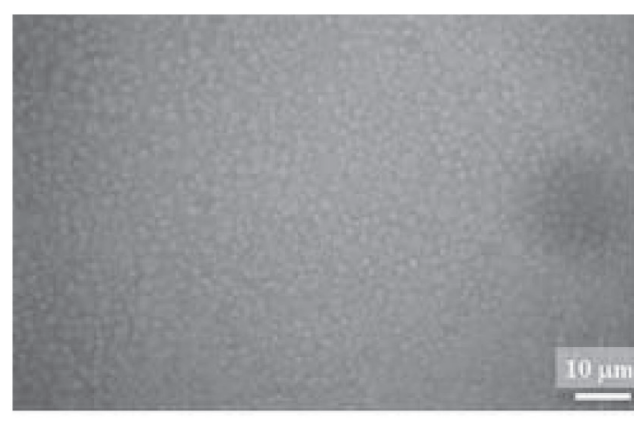

(b)

Fig. 3 (a) A ternary phase diagram of the water $/ \mathrm{C}_{12} \mathrm{EO}_{8} /$ liquid paraffin system at $25^{\circ} \mathrm{C}$ and a photograph of $\mathrm{O} / \mathrm{H}_{1}$ emulsions containing $80 \mathrm{wt} \%$ liquid paraffin, adapted from reference ${ }^{38)}$; (b) a microscopic image of $\mathrm{O} / \mathrm{H}_{1}$ emulsions, reprinted with permission from ref. 24(Langmuir 28, 11707-11719(2012). (C)(2012) American Chemical Society). 
Table 2 The stabilities of $\mathrm{O} / \mathrm{H}_{1}$ and $\mathrm{O} / \mathrm{I}_{1}$ emulsions after $24 \mathrm{~h}$ at $25^{\circ} \mathrm{C}$. Adapted from reference ${ }^{38)}$.

\begin{tabular}{|c|c|c|c|c|c|c|c|c|c|}
\hline \multicolumn{10}{|c|}{$\mathrm{O} / \mathrm{H}_{1}$ gel emulsion after $24 \mathrm{~h}$ at $25^{\circ} \mathrm{C}$} \\
\hline Oil content $(w t \%)$ & 30 & 35 & 40 & 45 & 50 & 60 & 70 & 80 & 90 \\
\hline Heptane & $\times$ & $x$ & $\times$ & $\times$ & $\times$ & $\times$ & $\times$ & $\times$ & $x$ \\
\hline Octane & $x$ & $x$ & $\times$ & $\times$ & $x$ & $x$ & $x$ & $x$ & $x$ \\
\hline Decane & $x$ & $x$ & $\times$ & $\times$ & $x$ & $\times$ & $\times$ & $x$ & $x$ \\
\hline Dodecane & $x$ & $x$ & $x$ & $\times$ & $x$ & $x$ & $\times$ & $x$ & $x$ \\
\hline Tetradecane & $x$ & $x$ & $x$ & $\times$ & $x$ & $x$ & $x$ & $\times$ & $x$ \\
\hline Hexadecane & $\times$ & $x$ & $\times$ & $\times$ & $\times$ & $\times$ & $x$ & $x$ & $x$ \\
\hline Squalane & $\bigcirc$ & O & O & O & $x$ & $\times$ & $\times$ & $x$ & $x$ \\
\hline Liquid paraffin & 0 & $\bigcirc$ & $\bigcirc$ & $\bigcirc$ & 0 & $\bigcirc$ & $\bigcirc$ & $\bigcirc$ & $x$ \\
\hline \multicolumn{10}{|c|}{$\mathrm{O} / \mathrm{I}_{1}$ gel emulsion after $24 \mathrm{~h}$ at $25^{\circ} \mathrm{C}$} \\
\hline Heptane & $\bigcirc$ & $\bigcirc$ & O & O & $\bigcirc$ & $\bigcirc$ & $\bigcirc$ & $\bigcirc$ & $x$ \\
\hline Octane & $\bigcirc$ & $\bigcirc$ & O & $\bigcirc$ & $\bigcirc$ & $\bigcirc$ & $\bigcirc$ & $\bigcirc$ & $x$ \\
\hline Decane & $\bigcirc$ & $\bigcirc$ & $\bigcirc$ & $\bigcirc$ & $\bigcirc$ & $\bigcirc$ & $\bigcirc$ & $\bigcirc$ & $x$ \\
\hline Dodecane & $\bigcirc$ & $\bigcirc$ & $\bigcirc$ & $\bigcirc$ & $\bigcirc$ & 0 & $\bigcirc$ & $\bigcirc$ & $\bigcirc$ \\
\hline Tetradecane & $\bigcirc$ & $\bigcirc$ & O & O & O & $\bigcirc$ & $\bigcirc$ & $\bigcirc$ & $\bigcirc$ \\
\hline Hexadecane & $\bigcirc$ & $\bigcirc$ & O & O & O & $\bigcirc$ & $\bigcirc$ & $\bigcirc$ & 0 \\
\hline Squalane & $\bigcirc$ & $\bigcirc$ & $\bigcirc$ & $\bigcirc$ & $\bigcirc$ & $\bigcirc$ & $\bigcirc$ & $\bigcirc$ & 0 \\
\hline Liquid paraffin & 0 & 0 & 0 & 0 & 0 & 0 & 0 & 0 & 0 \\
\hline
\end{tabular}

Gel emulsion, $\times$ oil-separated

concentration. One drawback of $\mathrm{O} / \mathrm{H}_{1}$ emulsions is the short duration of their stability relative to that of $\mathrm{O} / \mathrm{I}_{1}$ emulsions, as mentioned by Alam and Aramaki ${ }^{38)}$. A comparison of the stabilities of $\mathrm{O} / \mathrm{H}_{1}$ and $\mathrm{O} / \mathrm{I}_{1}$ emulsions is presented in Table 2. One could assume that the viscosity of the $\mathrm{H}_{1}$ phase is lower than that of the $\mathrm{I}_{1}$ phase $^{62)}$; as a result, the viscosity of $\mathrm{O} / \mathrm{I}_{1}$ emulsions is higher than that of $\mathrm{O} / \mathrm{H}_{1}$ emulsions ${ }^{63)}$. The rate of the emulsion-breaking processes is thus negligible in the case of $\mathrm{O} / \mathrm{I}_{1}$ emulsions; hence, $\mathrm{O} / \mathrm{I}_{1}$ emulsions show prolonged stability.

\subsection{Reversed liquid crystal-based emulsions}

Similar to the normal type of liquid crystalline mesophases, reversed lyotropic liquid crystals are also interesting soft materials because they allow improved design functionality in food products, drug delivery, materials synthesis and structural biological applications ${ }^{64-72)}$. Despite the variety of potential applications, reversed liquid crystals have not been studied to a great extent ${ }^{73-76)}$. Reversed liquid crystals have high viscosity, allowing preparation of reversed LC-based emulsions ${ }^{77-79)}$. Uddin et $a{ }^{77)}$ and Watanabe et $a l{ }^{78)}$ have shown that the reversed cubic phase can act as a continuous phase to separate the water droplets (dispersed phase), and, due to its high viscosity, the formed emulsions show prolonged stability. The authors noted that the LC must melt during preparation of reversed LC-based emulsions, similar to the case of normal LC-based emulsions. Rodriguez et al. ${ }^{80)}$ later studied reversed cubic phase-based emulsions $\left(\mathrm{W} / \mathrm{I}_{2}\right)$ in Pluronic L-121 systems, and the modulation of the self-assembled structure in the presence of water was studied by small angle X-ray scattering and dynamic oscillatory measurement. The authors reported that the shape of the droplets is polyhedral and polydisperse, despite the use of water as the dispersed phase. A microscopic image of a reversed cubic phase-based emulsion is shown in Fig. 4.

Recently, May et $a l^{50)}$ have studied the phase behavior of a Pluronic surfactant $(\mathrm{EO})_{5}(\mathrm{PO})_{68}(\mathrm{EO})_{5}(\mathrm{P}-121)$ system in the presence of hexane and evaluated the formation of reversed LC-based emulsions, as well as water in both reversed cubic $\left(\mathrm{W} / \mathrm{I}_{2}\right)$ and reversed hexagonal phase $\left(\mathrm{W} / \mathrm{H}_{2}\right)$ emulsions in the Pluronic system(Fig. 5). The authors have explained that reversed cubic or hexagonal phases could be induced from the reverse micellar solution with the addition of water and then used as a continuous phase to stabilize the excess water phase. The reversed LC-based emulsions can be formulated in the two phase region, $\mathrm{H}_{2}+$ $\mathrm{W}$ and $\mathrm{I}_{2}+\mathrm{W}$, in Fig. 5 .

May et $a l .{ }^{50)}$ explained the relationship between the microstructure of the surfactant self-assembled structure and 

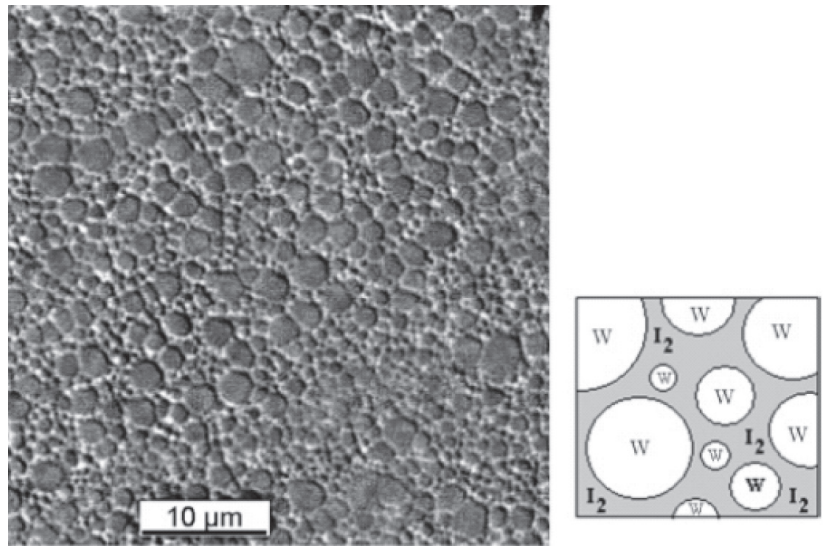

Fig. 4 Reversed cubic phase-based emulsion $\left(W / I_{2}\right)$, adapted from ref. 80 .

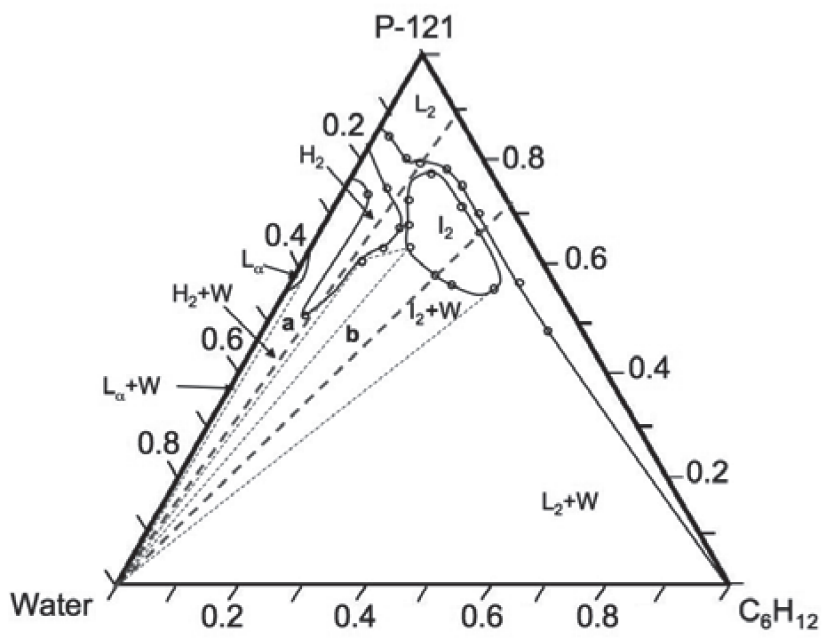

Fig. 5 Phase diagram of the water/ $(\mathrm{EO})_{5}(\mathrm{PO})_{68}(\mathrm{EO})_{5}$ $(\mathrm{P}-121) / \mathrm{C}_{6} \mathrm{H}_{12}$ system at $25^{\circ} \mathrm{C}$. Solid lines indicate one-phase boundaries. The following phases are shown: $\mathrm{L}_{\alpha}$, lamellar; $\mathrm{H}_{2}$, reverse hexagonal phase; $I_{2}$, reverse micellar cubic phase; $\mathrm{L}_{2}$, reverse micellar solution. $\mathrm{W}$ indicates excess water. The two thick dashed lines, labeled a and $\mathbf{b}$, are the water-addition paths followed in this study at a constant polymer/oil ratio: $\mathrm{P} / \mathrm{O}=$ $90 / 10$ in path a, and $\mathrm{P} / \mathrm{O}=72.5 / 27.5$ in b. Reproduced from ref. 50 .

the formation (and stability) of reversed LC-based emulsions. The rheological behavior of reversed LC-based emulsions was also studied.

\subsection{Nonaqueous liquid crystal-based emulsions}

As mentioned above, the formation of LCs is possible in nonaqueous media ${ }^{25,26,81)}$. However, LC-based emulsions in nonaqueous systems are not widely reported ${ }^{79-81)}$. Recently, Sharma and Warr ${ }^{81)}$ reported an LC-based emulsion in nonaqueous system; they have rationally used an ionic liquid instead of water and a nonionic surfactant, which forms a hexagonal phase $\left(\mathrm{H}_{1}\right)$, and perfluoromethyldecalin (PFMD) was incorporated as the dispersed phase. After adequate mixing, Sharma and Warr obtained highly viscous $\mathrm{O} / \mathrm{H}_{1}$ emulsions; they have also studied the microstructure of LCs in nonaqueous systems with the help of SAXS analysis. However, detailed studies of $\mathrm{O} / \mathrm{H}_{1}$ emulsions remain an interesting matter and could be explored in the near future.

\section{Transparent LC-based emulsions}

In general, the physical appearance of an emulsion is milky or translucent due to the difference of refractive index between the dispersed and continuous phases if the droplet size and volume fraction are moderate. Transparent LC-based emulsions can be obtained by adjusting refractive index difference by the factors such as the nature of the surfactant $^{48)}$ or oil ${ }^{38,51)}$, the addition of high refractive index solvent $^{3,46)}$ and the temperature.

Rodriguez $e t a l{ }^{3)}$ described that the refractive index of the continuous phase changes with the addition of glycerol. At a certain concentration of glycerol, the refractive indices of the continuous and dispersed phases are equal, and the translucent emulsions become transparent. Alam and Aramaki ${ }^{46,61)}$ also obtained transparent LC-based emulsions by adding a guest solvent with high refractive index (such as glycerol), as shown in Fig. 6 .

However, the structure of the emulsions changes with increased concentration of the guest solvent. In fact, one can control the structure of the emulsions, as well as their transparency, by considering the amount of guest solvent; otherwise, an excess amount of guest solvent changes the structure of the emulsion to a micellar phase ${ }^{61)}$. Recently, Takahashi $e t ~ a l .{ }^{49)}$ described transparent LC-based emulsions. The authors have explained the emulsion transparency with the help of refractive index and light transmittance measurements, which are well correlated with the Rodriguez observations ${ }^{3)}$. According to Takahashi et al. ${ }^{49)}$, the refractive index of the $\mathrm{I}_{1}$ continuous phase is lower than that of the dispersed phase (isododecane, 1.42); the addition of glycerol increases the refractive index of the $\mathrm{I}_{1}$ phase, which matches that of the dispersed phase at a certain concentration of glycerol (the wt. fraction of glycerol is 0.4) (Fig. 7a), and, as a result, the translucent emulsion becomes transparent. The transmittance of visible light reaches its maximum value at that concentration of glycerol, as shown in Fig. 7b. Upon further increase of the glycerol content, the microstructure of the liquid crystals $\left(\mathrm{I}_{1}\right)$ modulated to the hexagonal phase $\left(\mathrm{H}_{1}\right)$, and the emulsion structure changes from $\mathrm{O} / \mathrm{I}_{1}$ to $\mathrm{O} / \mathrm{H}_{1}$; a similar observation was also reported by Alam et $a l .{ }^{46)}$ Although changing 

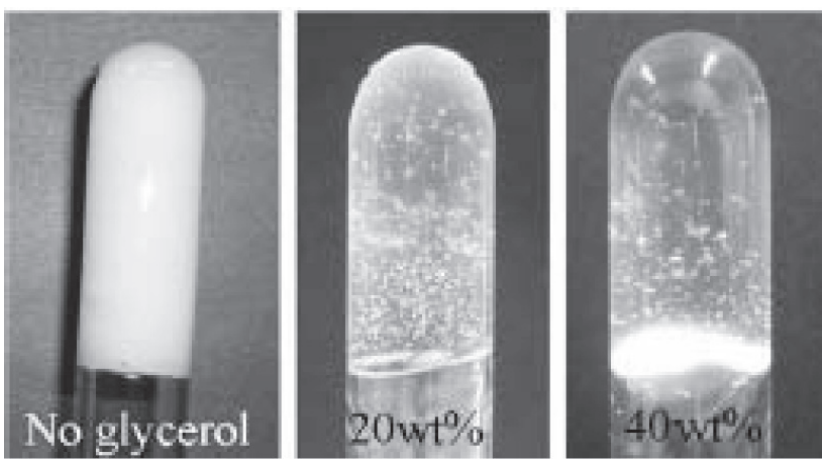

Fig. 6 Transparent LC-based emulsions obtained by addition of glycerol. Adapted from ref. 46.
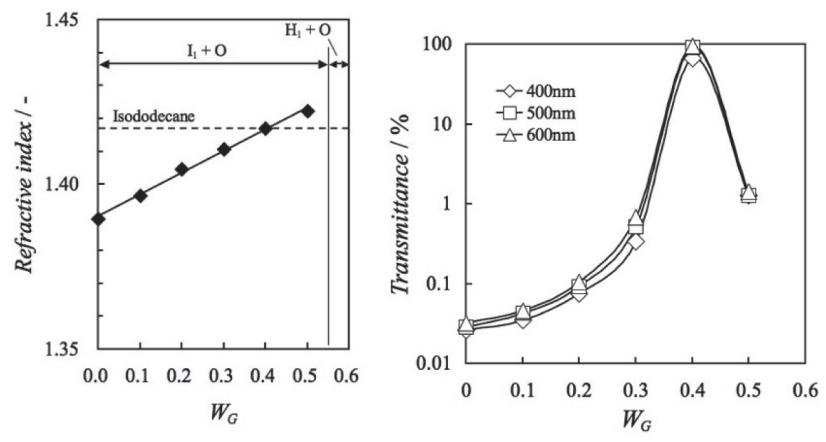

Fig. 7 (a) The change in refractive index and (b) transmittance of the $\mathrm{O} / \mathrm{I}_{1}$ emulsion at a fixed composition of (water + glycerol $) / \mathrm{C}_{12} \mathrm{EO}_{\mathrm{n}}$ /isododecane $=24 / 16 / 60$ at $25^{\circ} \mathrm{C}$, adapted from ref. 49 .

the transparency of the emulsions is interesting, one must remember that excess guest solvent could hamper the emulsion structure.

Tuning refractive index either droplet or continuous phase of the LC-based emulsions allows to obtain the transparent emulsions although the rheological properties changes and also, in some cases, phase transition can happen. Further studies regarding relationship of transparency and physical property can be expected. Temperature is also a parameter to tune refractive index, which has yet been studied. Until now, any application studies of the transparent LC-based emulsions have not been reported. A simple application for cosmetic gel formulation may be possible in near future but studying molecular dynamics or reactions at water-oil interface or in a confined domain are also expected.

\section{RHEOLOGICAL PROPERTIES OF LC-BASED EMULSIONS}

The rheology or microrheology microrheology ${ }^{22,23)}$ of liquid crystals is an interesting subject in colloid science or soft materials. There are many articles in the literature that deal with the rheology of LCs; therefore, our discussion refrains from that topic. Instead, we will focus on the rheology of LC-based emulsions. Rodriguez et al..$^{36)}$ observed that the addition of oil to the LC increases its viscosity, and the maximum viscosity was obtained at the maximum oil solubilization point. Increasing the oil content in the LC presumably also increases the core of the micelles; as a result, the neighboring micellar interaction increases, which manifests as the increase in LC viscosity. A similar observation was also reported in other surfactant systems ${ }^{38,48,84}$. The rheology of LC-based emulsions is of crucial importance because of the information gained of the status of the products, such as stability, aging, transportation and formation. Knowledge of the micro-structural modulation of the emulsions is also helpful. From the last few decades, there are several articles that describe the rheology of conventional highly concentrated emulsions ${ }^{85-87}$. Rodriguez et $a l .^{36)}$ first described the rheology of LC-based emulsions, and Alam et al. ${ }^{4,38,47,51)}$ later justified that the rheology of LC-based emulsions is different than that of conventional highly concentrated gel emulsions ${ }^{57,86)}$. The elastic modulus, $G^{\prime}$ of the emulsions is nearly frequency independent and remains over the viscous modulus, $G^{\prime \prime}$ (Fig. 8a) characteristics for gel type structure. However, the viscoelastic moduli and the viscosity of LC-based emulsions decrease with increasing the dispersed phase volume fraction (Fig. 8a and 8b), whereas anomalous behavior was observed in the case of highly concentrated emulsions. As mentioned above, the rheology of LC-based emulsions is mainly controlled by the volume fraction of the LC; as a result, increasing the oil concentration decreases the LC volume fraction, which decreases the emulsion viscosity (Fig. 8b). Nonetheless, the highest complex viscosity $\left(I \eta^{*}\right.$ I) and elastic modulus $\left(G^{\prime}\right)$ are observed at the boundary between the LC (maximum oil solubility) and LC basedemulsions (Fig. 8b).

At present, numerous articles can be found in the literature describing the rheology of LC-based emulsions in different surfactant systems ${ }^{47-49,52,63,84)}$. It is interesting that the physical and thermal stability of LC-based emulsions can be tuned by considering the type of continuous phase. It was reported ${ }^{38)}$ that the viscosity of cubic phase-based emulsions $\left(\mathrm{O} / \mathrm{I}_{1}\right)$ is higher than that of hexagonal phasebased emulsions $\left(\mathrm{O} / \mathrm{H}_{1}\right)$; however, the latter system shows higher thermal stability than the former, as shown in Fig. 9.

Recently, May et $a l^{50)}$ evaluated the yield stress of reversed LC-based emulsions as a function of water content in a steady-state flow measurement, as shown in Fig. 10. The yield stress value of the $\mathrm{I}_{2}$ phase is higher than that of the $\mathrm{H}_{2}$ phase; however, a linear relationship between shear rate and shear stress was not observed, as shown in the inset of Fig. 10. A constant yield stress value was found in both $\mathrm{I}_{2}$ and $\mathrm{H}_{2}$ phases, and the value decreases with the addition of water in the emulsion region. The decreasing yield 


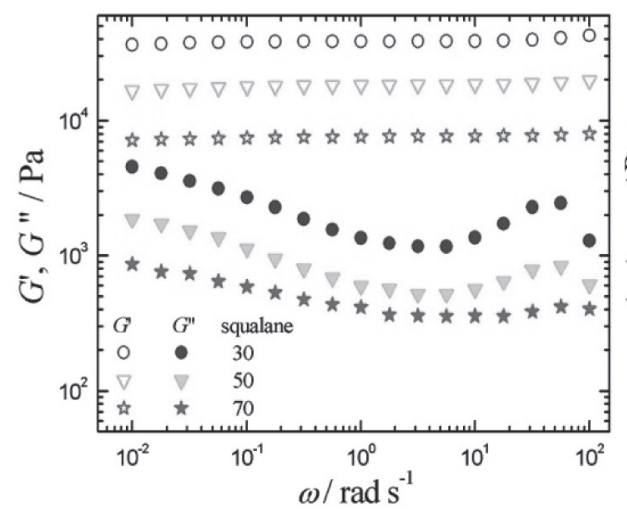

(a)

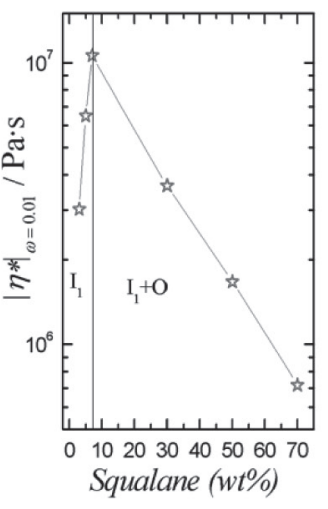

(b)

Fig. 8 Rheology of LC-based emulsions at different concentrations of squalane, (a) viscoelastic properties (viscous modulus, $G^{\prime \prime}$ and elastic modulus, $\left.G^{\prime}\right)(\mathrm{b})$ complex viscosity, $\left|\eta^{*}\right|$, and elastic modulus, $G^{\prime}$, at a fixed frequency, adapted from ref. 47.

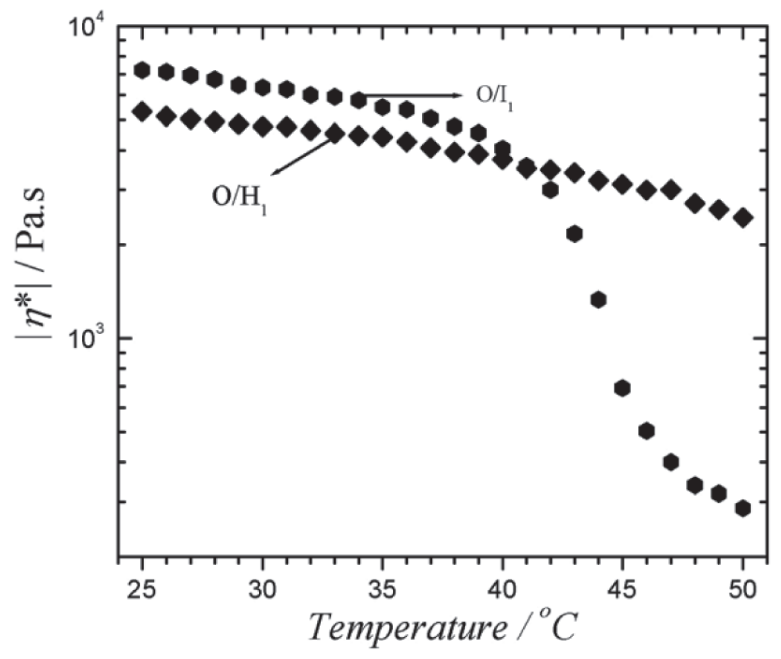

Fig. 9 Temperature-sweep measurement of cubic- $(\mathrm{O} /$ $\left.\mathrm{I}_{1}\right)$ and hexagonal- $\left(\mathrm{O} / \mathrm{H}_{1}\right)$ based emulsions, containing $80 \mathrm{wt} \%$ liquid paraffin in different water/ $\mathrm{C}_{12} \mathrm{EO}_{8}$ ratios $\left(60 / 40\right.$ for $\mathrm{I}_{1}$ and $40 / 60$ for $\mathrm{H}_{1}$ ), adapted from ref. 38.

stress in the emulsion region is due to the lower volume fraction of the LC, similar to what was reported by Rodriguez et $a l .{ }^{36)}$ and Alam et $a l^{38,47,51)}$.

\section{PREPARATION OF DUAL MESO/MACROPOROUS MATERIALS BY USING LC-BASED EMULSIONS AS TEMPLATES}

Conventional highly concentrated emulsions (HIPREs) that were developed a few decades ago have been used as templates for the preparation of macroporous materials ${ }^{88-93)}$.

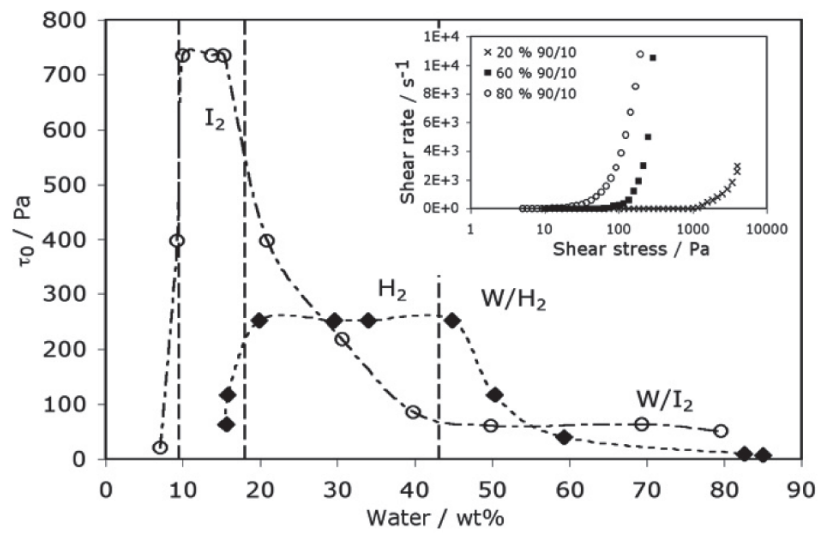

Fig. 10 Yield stress values as a function of water weight fraction following two paths: $\mathrm{P} / \mathrm{O}=$ $90 / 10$, path $\mathbf{a}, \boldsymbol{\nabla}$, and $\mathrm{P} / \mathrm{O}=72.5 / 27.5$, path $\mathbf{b}$, $\bigcirc$ at $25^{\circ} \mathrm{C}$. Inset: Rheogram (shear rate versus shear stress) for samples at fixed $\mathrm{P} / \mathrm{O}=90 / 10$ (path a) and different water concentrations $(20$ $(\times), 60(\square), 80 \mathrm{wt} \%(\bigcirc)$, showing nonNewtonian behavior, as the relationship between both parameters is non-linear. Other notations are as in Fig. 5, adapted from ref. 50. Here, $\mathrm{P}$ indicates pluronic surfactant $(\mathrm{EO})_{5}$ $(\mathrm{PO})_{68}(\mathrm{EO})_{5}(\mathrm{P}-121)$ and $\mathrm{O}$ indicating oil phase $\left(\mathrm{C}_{6} \mathrm{H}_{12}\right)$, other notations are same as Fig. 5 .

The polymer foam was obtained by the polymerization of the continuous phase; as a result, the droplets of the emulsions preserve the pores of the porous materials. The obtained materials possess mainly macropores; as a result, the surface area was not very high. Recently, Esquena ${ }^{94)}$ prepared a dual structure of meso/macroporous materials 


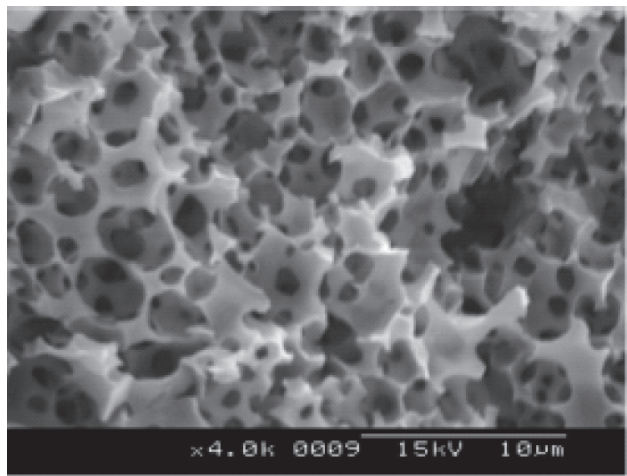

(a)

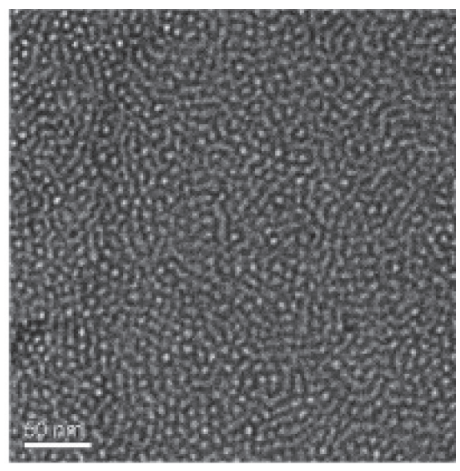

(b)

Fig. 11 (a) SEM and (b) TEM images of meso/macroporous silica materials formed by using $\mathrm{O} / \mathrm{I}_{1}$ emulsions as templates, reprinted with permission from ref. 16 (Langmuir 28, 12334-12340 (2012). (C)(2012) American Chemical Society).

by using LC-based emulsions as templates. The materials were obtained by the polymerization of the continuous phase. The emulsion droplets provide the macropores, whereas the LC (continuous phase) gives the mesoporous structure shown in Fig. 11. The obtained materials possess high surface area $\left(\approx 550 \mathrm{~m}^{2} / \mathrm{g}\right)$, and the total pore volume is higher than $90 \mathrm{wt} \%$. It is also possible by this method to obtain relatively large (centimeter size) monolithic materials which give advantages for applications such as catalytic support, filters, chromatographic adsorbents. Since the Esquena's report ${ }^{94)}$ is the first one, we can expect more use of the LC-based emulsions for material synthesis.

\section{SUMMARY}

In this review article, we have summarized recent developments in the formation, stability and rheology of liquid crystal-based emulsions (O/LC and W/LC-type emulsions). Different types of liquid crystals, which could form in aqueous and nonaqueous media, facilitate the formation of LC-based emulsions. However, there remains much work to be performed on LC-based emulsions to determine the mechanism of microstructural arrangement at a microscopic length. Transparent LC-based emulsions are an interesting issue from an industrial point of view regarding the formulation of new products. The architecture of the LC mainly controls the physical properties of the emulsions but also provides the opportunity to design advanced materials with different length scales that could be useful in a variety of applications.

\section{ACKNOLWLEDGEMENTS}

Alam, M. M. is thankful to the Ministry of Education, Culture, Sports, Science and Technology (MEXT) of Japan for providing scholarship during $\mathrm{Ph}$. D study.

\section{REFERENCES}

1) Rodriguez, C.; Lazzari, M. Emulsions with structured continuous phases. Curr. Opin. Colloid Interface Sci. 13, 198-205 (2008).

2) Friberg, S. E.; Solans, C.; Gan-zuo, L. Solubilization in nonaqueous lyotropic liquid crystals. Mol. Cryst. Liq. Cryst. 109, 159-168(1984).

3) Rodriguez, C.; Shigeta, K.; Kunieda, H. Cubic phase based concentrated emulsions. J. Colloid Interface Sci. 223, 197-204(2000).

4) Alam, M. M. Formation and rheological behavior of hexagonal and cubic phase based gel emulsion. Ph. D. Dissertation, Yokohama National University (2009). (DOI: http://hdl.handle.net/10131/6693).

5) Loudet, J. C.; Poulin, P. Liquid crystal emulsion. $J$. Dispers. Sci, Technol. 23, 143-154(2002).

6) Yada, M.; Yamamoto, J.; Yokoyama, H. Spontaneous formation of regular defect array in water in cholesteric liquid crystal emulsions. Langmuir 18, 7436-40 (2002).

7) Perrin, P.; Lafuma, F. Low hydrophobically modified poly (acrylic acid) stabilizing macroemulsions: relationship between copolymer structure and emulsions properties. J. Colloid Interface Sci. 197, 317-326 (1998).

8) Malone, M. E.; Appelqvist, I. A. M. Gelled emulsion particles for the controlled release of lipophilic volatiles during eating. J. Control. Release. 90, 227-241 


\section{M. Alam and K. Aramaki}

(2003).

9) Dickinson, E. Structure formation in casein-based gels, foams and emulsions. Colloids Surf. A 288, 3-11 (2006).

10) Ghosh, S.; Rousseau, D. Triacylglycerol interfacial crystallization and shear structuring in water in oil emulsions. Cryst. Growth Des. 12: 4944-4954(2012).

11) Rousseau, D. Trends in structuring edible emulsions with pickering fat crystals. Curr. Opin. Colloid Interface Sci. 18, 283-291 (2013).

12) Vilchez, A.; Rodríguez, C.; Esquena, J.; Menner, A.; Bismarck, A. Macroporous polymers obtained in highly concentrated emulsions stabilized solely with magnetic nanoparticles. Langmuir 27, 13342-13352(2011).

13) Whitby, C. P.; Lotte, L.; Lang, C. Structure of concentrated oil in water pickering emulsions. Soft Matter 8, 7784-7789 (2012).

14) Gupta, R.; Rousseau, D. Surface-active solid lipid nanoparticles as pickering stabilizers for oil-in-water emulsions. Food Func. 3, 302-311 (2012).

15) Esquena, J.; Izquierdo, P.; Kunieda, H.; Solans, C. Proceedings of the 1st Iberian meeting on colloids and interfaces. Spain: Salamanca; 2005.

16) Esquena, J.; Nestor, J.; Vilchez, A.; Aramaki, K.; Solans, C. Preparation of mesoporous/macroporous materials in highly concentrated emulsions based on cubic phase by a single step method. Langmuir 28, 12334-12340 (2012).

17) Mitchell, D. J.; Tiddy, G. J. T.; Waring, L.; Bostock, T.; McDonald, M. P. Phase behavior of polyoxyethylene surfactant with water. J. Chem. Soc. Faraday Trans. 79, 975-1000 (1983)

18) Li, X.; Kunieda, H. Solubilization of micellar cubic phases and their structural relationships in anionic cationic surfactant dodecane water systems. Langmuir 16, 10092-10100 (2000).

19) Alam, M. M.; Varade D.; Aramaki, K., Solubilization of triglycerides in liquid crystals of nonionic surfactant. $J$. Colloid Interface Sci. 325, 243-249 (2008).

20) Luzzati, V.; Vargas, R.; Gulik, A.; Mariani, P.; Seddon, J.; Rivas, E. Lipid polymorphism: a correction. The structure of the cubic phase of extinction symbol Fd-consists of two types of disjointed reverse micelles embedded in a three-dimensional hydrocarbon matrix. Biochemistry 31, 279-285 (1992).

21) Seddon, J.; Zeb, N.; Templer, R. H.; McElhaney, R. N.; Mannock, D. A. An Fd3m lyotropic cubic phase in a binary glycolipid/water system. Langmuir 12, 52505253 (1996).

22) Alam, M. M. Mezzenga, R. particle tracking microrheology of lyotropic liquid crystals. Langmuir 27, 61716178(2011).

23) Alam, M. M. The effect of ethanol on the phase behavior and microrheology of liquid crystals. Liquid Crys- tals 39, 1427-1434(2012).

24) Sharma, S. C.; Warr, G. G. Phase behavior, self-assembly, and emulsification of Tween 80/water mixtures with limonene and perfluoromethyldecalin. Langmuir 28, 11707-11719(2012).

25) Shrestha, L. K.; Sato, T.; Aramaki, K. Phase behavior and self-organized structures of diglycerol monolaurate in different nonpolar organic solvents. Langmuir 23, 6606-6613 (2007).

26) Wang, X.; Chen, X.; Zhao, Y.; Yue, X. Li, Q.; Li, Z. Nonaqueous lyotropic liquid-crystalline phases formed by gemini surfactants in a protic ionic liquid. Langmuir 28, 2476-2484(2012).

27) Hyde, S. T.; Ericsson, B.; Andersson, S.; Larsson, K. Z. A cubic structure consisting of a lipid. Kristallogr. 168, 213-219 (1984).

28) Krog, N. Food Emulsifiers and Their Chemical and Physical Properties. In Food Emulsions; Friberg, S. E.; Larsson, K. Eds.; Marcel Dekker Inc.: New York, p 141 (1997).

29) Mariani, P.; Rustichelli, F.; Saturni, L.; Cardone, L. Stabilization of the monoolein Pn3m cubic structure on trehalose glasses. Eur. Biophys. J 28, 294-301 (1999).

30) Larsson, K. Aqueous dispersions of cubic lipid water phases. Curr. Opin. Colloid Interface Sci. 5, 64-69 (2000).

31) Mezzenga, R.; Schurtenberger, P.; Burbidge, A.; Michel, M. Understanding foods as soft materials. Nature Mat. 4, 729-740 (2005).

32) Friberg, S.; Mandell, L.; Larsson, M. Mesomorphous phases, a factor of importance for the properties of emulsions. J. Colloid Interface Sci. 29, 155-156 (1969).

33) Al-Bawab, A.; Friberg, S. E. Some pertinent factors in skin care emulsion. Adv. Colloid Interface Sci. 123126, 313-322 (2006).

34) Lynch, M. L.; Kochvar, K. A.; Burns, J. L.; Laughlin, R. G. Aqueous-phase behavior and cubic phase containing emulsions in the $\mathrm{C}_{12} \mathrm{E}_{2}$-water system. Langmuir 16, 3537-3542 (2000).

35) Kunieda, K.; Tanimoto, M.; Shigeta, K.; Rodriguez, C. Highly concentrated cubic phase emulsions: Basic Study on D-phase emulsification using isotropic gels. J. Oleo Sci. 50, 633-639(2001).

36) Rodriguez, C.; Roman, G. M, Kunieda, H. Rheology and dynamics of micellar cubic phases and related emulsions. Langmuir 20, 5235-5240 (2004).

37) Rodriguez, C.; Shrestha, L. K.; Varade, D.; Aramaki, K.; Maestro, A.; Lopez-Quentala, A.; Solans, C. Formation and properties of reverse micellar cubic liquid crystals and derived emulsions. Langmuir 23, 11007-11014 (2007).

38) Alam, M. M.; Aramaki, K. Hexagonal phase based gel emulsion $\left(\mathrm{O} / \mathrm{H}_{1}\right.$ gel emulsion $)$ : formation and rheology. 
Langmuir 24, 12253-12259(2008).

39) Kunieda, H.; Ozawa, K.; Huang, K. L. Effect of oil on the surfactant molecular curvatures in liquid crystals. J. Phys. Chem. B 102, 831-838(1998).

40) Kunieda, H.; Solans, C.; Shida, N.; Parra, J. L. The formation of gel emulsions on a water/nonionic surfactant/oil system. Colloids Surfaces 24, 225-237 (1987).

41) Kunieda, H.; Yano, N.; Solans, C. The stability of gel emulsions in a water/nonionic/oil system. Colloids Surfaces 36, 313-322(1989).

42) Kunieda, H.; Evans, D. F.; Solans, C.; Yoshida, M., The structure of gel emulsions in a water/nonionic surfactant/oil systems. Colloids Surfaces 47, 35-43 (1990).

43) Pons, R.; Carrera, I.; Erra. P.; Kunieda, H.; Solans, C. Novel preparation methods for highly concentrated water oil emulsions. Colloids Surfaces A 91, 259-266 (1994).

44) Kunieda, H.; Fukui, Y.; Uchiyama, H.; Solans, C. Spontaneous formation of highly concentrated water in oil emulsions (gel emulsions). Langmuir 11, 1966-1971 (1995).

45) Princen, H. M. Rheology of foams and highly concentrated emulsions. J. Colloid Interface Sci. 91, 160175 (1983).

46) Alam, M. M.; Shrestha, L. K.; Aramaki, K. Glycerol effects on the formation and rheology of cubic phase and related gel emulsion. J. Colloid Interface Sci. 329, 366-371 (2009).

47) Alam, M. M.; Ushiyama, K.; Aramaki, K. Phase behavior, formation and rheology of cubic Phase and related gel emulsion in Tween 80/water/oil systems. J. Oleo Sci. 58, 361-367(2009).

48) Alam, M. M, Sugiyama, Y.; Watanabe, K.; Aramaki, K. Phase behavior and rheology of oil-swollen micellar cubic phase and gel emulsions in nonionic surfactant systems. J. Colloid Interface Sci. 341, 267-272 (2010).

49) Takahashi, T.; Sugiyama, Y.; Watanabe, K.; Aramaki, K. Influence of surfactant hydrophilicity on the formation of transparent $\mathrm{O} / \mathrm{I}_{1}$ type emulsions. J. Oleo Sci. 60, 403-409 (2011).

50) May, A.; Aramaki, K.; Gutierrez, J. M. Phase behavior and rheological analysis of reverse liquid crystals and $\mathrm{W} / \mathrm{I}_{2}$ and $\mathrm{W} / \mathrm{H}_{2}$ gel emulsions using an amphiphilic block copolymer. Langmuir 27, 2286-2298(2011).

51) Alam, M. M.; Aramaki, K. Effect of molecular weight of triglycerides on the formation and rheological behavior of cubic and hexagonal phase based gel emulsions. J. Colloid Interface Sci. 336, 329-334(2009).

52) Alam, M. M.; Matsumoto, Y.; Aramaki, K. Effects of surfactant hydrophilicity on the oil solubilization and rheological behavior of a nonionic hexagonal phase. In press, J. Surfact. Deterg. 2013 (DOI: 10.1007/s11743013-1465-1).
53) Suzuki, T.; Takei, H.; Yamazaki, S. Formation of fine three-phase emulsions by the liquid crystal emulsification method with arginine $\beta$-branched monoalkyl phosphate. J. Colloid Interface Sci. 129, 491-500 (1989).

54) Nakama, Y.; Siojima, Y.; Harusawa, F. O/W Type Emulsions using Liquid Crystal formed at Oil / Water Interface. J. Jpn. Oil Chem. Soc. 47, 585-590(1998).

55) Salager, J. L.; Forgiarini, A.; Márquez, L.; Pena, A.; Pizzino, A.; Rodriguez, M. P.; Rondon-Gonzalez, M. Using emulsion inversion in industrial processes. Adv. Colloid Interface Sci. 108-109, 259-272 (2004).

56) Uddin, M. H.; Kanei, N.; Kunieda, H. Solubilization and emulsification of perfume in discontinuous cubic phase. Langmuir 16, 6891-6897 (2000).

57) Pal, R. Rheology of high internal phase ratio emulsions. Food Hydrocolloids 20, 997-1005(2006).

58) Shigeta, K.; Rodriguez, C.; Kunieda, H. Solubilization of oil in discontinuous cubic liquid crystal in poly (oxyethylene) oleyl ether systems. J. Disper. Sci. Technol. 21, 1023-1042 (2000).

59) Uddin, M. H.; Kunieda, H.; Solans, C. Highly concentrated cubic phase-based emulsions. In: Esumi K, Ueno M, editors. Structure-Performance Relationships in Surfactants. 2nd edition. New York: Marcel Dekker; pp. 559-626, (2003).

60) Horvath-Szabo, G.; Masliyah, J. H.; Czarnecki, J. Emulsion stability based on phase behavior in sodium naphthenates containing systems: gels with a high organic solvent content. J. Colloid Interface Sci. 257, 299309 (2003).

61) Alam, M. M.; Aramaki, K. Glycerol effect on the formation and rheology of hexagonal phase and related gel emulsion, J. Colloid Interface Sci. 336, 820-826 (2009).

62) Rodriguez, C.; Acharya, D. P.; Aramaki, K.; Kunieda, H. Structure and rheology of direct and reverse liquidcrystal phases in a block copolymer/water/oil system. Colloids Surface A 269, 59-66 (2009).

63) Matsumoto, Y.; Alam, M. M.; Aramaki, K. Phase behavior, formation, and rheology of cubic and hexagonal phase based gel emulsions in water/tetraglyceryl lauryl ether/oil systems. Colloids, Surface A 341, 27-32 (2009).

64) Sagalowicz, L.; Mezzenga, R.; Leser, M. E. Investigating reversed liquid crystalline mesophases. Curr. Opin, Colloid Interface Sci. 11, 224-229 (2006).

65) Negrini, R., Mezzenga, R. PH-responsive lyotropic liquid crystals for controlled drug delivery. Langmuir 27, 5296-5303 (2011).

66) Sagalowicz, L.; Leser, M. E.; Watzke, H. J.; Michel, M. Monoglyceride self assembly structures as delivery vehicles. Trends Food Sci. Technol. 17, 204-14(2006).

67) Boyd, B. J. Controlled release from cubic liquid crys- 
talline particles (cubosomes). In: Lynch ML, Spicer PT, editors. bicontinuous liquid crystals. Surf. Sci. Ser., New York: CRC Press;. p. 285-305 (2005).

68) Andersson, M.; Alfredsson, V.; Kjellin, P.; Palmqvist, A. E. C. Macroscopic alignment of silver nanoparticles in reverse hexagonal liquid crystalline templates. Nano Letters 2, 1403-1407 (2002).

69) Amar-Yuli, I.; Libster, D.; Aserin, A.; Garti, N. Solubilization of food bioactives within lyotropic liquid crystalline mesophases. Curr. Opin. Colloid Interface Sci. 14, 21-32 (2009).

70) Nguyen, T. H.; Hanley, T.; Porter, C. J. H.; Boyd, B. J. Nanostructured liquid crystalline particles provide long duration sustained-release effect for a poorly water soluble drug after oral administration. J. Control Release 153, 180-186 (2011).

71) Larsson, K.; Fontell, K.; Krog, N. Structural relationships between lamellar, cubic and hexagonal phases in monoglyceride-water systems. Possibility of cubic structures in biological systems. Chem. Phys. Lipids 27, 321-328(1980).

72) Seddon, J. M. An inverse face-centered cubic phase formed by diacylglycerol-phosphatidylcholine mixtures. Biochemistry 29, 7997-8002 (1990).

73) Alexandridis, P.; Olsson, U.; Lindman, B. A reverse micellar cubic phase. Langmuir 12, 1419-1422 (1996).

74) Minamikawa, H.; Hato, M. Reverse micellar cubic phase in a phytanyl-chained glucolipid/water system. Langmuir 14, 4503-4509 (1998).

75) Angelico, R.; Ceglie, A.; Olsson, U.; Palazzo, G. Phase diagram and phase properties of the system Lecithinwater-cyclohexane. Langmuir 16, 2124-2132 (2000).

76) Rodriguez, C.; Uddin, M. H.; Watanabe, K.; Furukawa, H.; Harashima, A.; Kunieda, H. Self-Organization, phase behavior, and microstructure of poly (oxyethylene) poly (dimethylsiloxane) surfactants in nonpolar oil. J. Phys. Chem. B 106, 22-29(2002).

77) Uddin, M.; Rodriguez, C.; Watanabe, K. Lopez-Quintela, A.; Kato, T.; Furukawa, H.; Harashima, A. Kunieda, H. Phase behavior and formation of reverse cubic phase based emulsion in water/poly (oxyethylene) poly (dimethylsiloxane) surfactants/silicone oil systems. Langmuir 17, 5169-5175 (2001).

78) Watanabe, K.; Kanei, N.; Kunieda, H. Highly concentrated emulsions based on the reverse micellar cubic phase. J. Oleo Sci. 51, 771-779(2002).

79) Mele, S.; Murgia, S.; Monduzzi, M. Monoolein based liquid crystals to form long-term stable emulsions. Colloids Surf A 228, 57-63(2003).

80) Rodriguez, C.; Shrestha, L. K.; Varade, D.; Aramaki, K.; Maestro, A.; Lopez Quintela, A.; Solans, C. Formation and properties of reverse micellar cubic liquid crystals and derived emulsions. Langmuir 23, 11007-11014
(2007).

81) Sharma, S. C.; Warr. G. G. A nonaqueous liquid crystal Emulsion: fluorocarbon oil in a hexagonal phase in an ionic liquid. J. Phys. Chem. Lett. 2, 1937-1939(2011).

82) Imhof, A.; Pine, D. J. Stability of nonaqueous emulsions. J. Colloid Interface Sci. 192, 368-374 (1997).

83) Riess, G.; Cheymol, A.; Hoerner, P.; Krikorian, R. Nonaqueous emulsions stabilized by block copolymers: application to liquid disinfectant-filled elastomeric films. Adv. Colloid Interface Sci. 108-109, 43-48 (2004).

84) Alam, M. M.; Hoshida, S.; Arima, S.; Aramaki, K. Lyotropic behavior of nonionic sugar surfactant and rheology of the liquid crystal. In press, J. Dispers. Sci. Technol. 2013(DOI:10.1080/01932691.2012.743862).

85) Mason, T. G.; Lacasse, M. D.; Grest, G. S.; Levine, D.; Bibette, J.; Weitz, D. A. Osmotic pressure and viscoelastic shear moduli of concentrated emulsions, Phys. Rev. E 56, 3150-3166 (1997).

86) Pal, R. Novel viscosity equations for emulsions of two immiscible liquids. J. Rheol. 45, 509-520 (2001).

87) Masalova, I.; Foudazi, R.; Malkin, A. The rheology of highly concentrated emulsions stabilized with different surfactants. Colloids Surf. A 375, 76-86 (2011).

88) Barby, D.; Haq, Z. Low density porous cross-linked polymeric materials and their preparation. European patent 0060138, 1982.

89) Ruckenstein, E.; Park, J. S. Hydrophilic hydrophobic polymer composites. J. Polym. Sci. Pol. Lett. 26, 529536 (1988).

90) Esquena, J.; Sankar, G. S. R. R.; Solans, C. Highly concentrated W/O emulsions prepared by the PIT method as templates for solid foams. Langmuir 19, 2983-2988 (2003).

91) Ghosh, G.; Vilcheza, J.; Esquenaa, J.; Solans, C.; Rodriguez, C. Preparation of ultra-light magnetic nanocomposites using highly concentrated Emulsions. Mat. Chem. Phys. 130, 786-793(2011).

92) Vilchez, S.; Perez-Carrillo, L. A. Miras, J.; Solans, C.; Esquena, J. Oil in alcohol highly concentrated emulsions as templates for the preparation of macroporous materials. Langmuir 28, 7614-7621 (2012).

93） Alam, M. M.; Miras, J.; Perez-Carrillo, L. A.; Vilchez, S.; Solans, C.; Imae, T.; Ujihara, M.; Esquena, J. Facile synthesis of dual micro/macroporous carbonaceous foams by templating in highly concentrated water-inoil emulsions. Microporous Mesoporous Mater. 182, 102-108 (2013).

94) Nestor, J.; Vilchez, A.; Solans, C.; Esquena, J. Facile synthesis of meso/macroporous dual materials with ordered mesopores using highly concentrated emulsions based on a cubic liquid crystal. Langmuir 29, 432-440 (2013). 